\title{
A close call: does the location of incision at cesarean delivery matter in patients with vasa previa? A case report. [version 1; peer review: 3 approved]
}

\author{
Werner M Neuhausser ${ }^{1}$, Laxmi V Baxi ${ }^{2,3}$ \\ ${ }^{1}$ Division of Reproductive Endocrinology \& Infertility, Beth Israel Deaconess Medical Center/Boston IVF, Harvard Medical School, \\ Boston, MA, USA \\ ${ }^{2}$ Adjunct Professor Ob-Gyn, New York University School of Medicine, New York, NY, USA \\ ${ }^{3}$ Professor Emerita, Clinical Obstetrics and Gynecology, Columbia University, New York, NY, USA
}

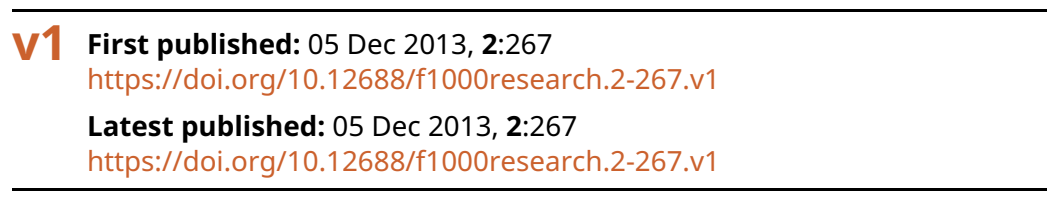

\section{Abstract}

We present here a case of vasa previa in a multipara, diagnosed at the time of her late second trimester ultrasonogram. The patient subsequently underwent an elective cesarean section after 37 weeks gestation, giving birth to a healthy child with an uneventful postpartum, neonatal and infant course. At the time of cesarean section, the incision was gradually deepened in layers through the myometrium by utmost care allowing the amniotic sac to protrude through the uterine incision hereby avoiding laceration of the vasa previa and its branches. Fetal exsanguination and a need for blood transfusion as well as a possible adverse neonatal course were therefore avoided.

\section{Open Peer Review \\ Approval Status \\ 12 \\ 23 \\ version 1 \\ 05 Dec 2013
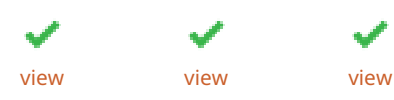 \\ 1. Conrad Chao, University of California, San Francisco, San Francisco, CA, USA \\ 2. Everett Magann, University of Arkansas for Medical Sciences, Little Rock, AR, USA \\ 3. Ryu Matsuoka, Showa University, Tokyo, Japan}

Any reports and responses or comments on the article can be found at the end of the article. 
Corresponding author: Laxmi V Baxi (laxmi.baxi@nyumc.org)

Competing interests: No competing interests were disclosed.

Grant information: The author(s) declared that no grants were involved in supporting this work.

Copyright: @ 2013 Neuhausser WM and Baxi LV. This is an open access article distributed under the terms of the Creative Commons Attribution License, which permits unrestricted use, distribution, and reproduction in any medium, provided the original work is properly cited. Data associated with the article are available under the terms of the Creative Commons Zero "No rights reserved" data waiver (CC0 1.0 Public domain dedication).

How to cite this article: Neuhausser WM and Baxi LV. A close call: does the location of incision at cesarean delivery matter in patients with vasa previa? A case report. [version 1; peer review: 3 approved] F1000Research 2013, 2:267

https://doi.org/10.12688/f1000research.2-267.v1

First published: 05 Dec 2013, 2:267 https://doi.org/10.12688/f1000research.2-267.v1 


\section{Case}

The CARE checklist submitted with this case report is accessible here.

A 27 year old, Caucasian gravida 4 para 3, was diagnosed with vasa previa at a 22 week anatomy scan. On ultrasound her right lateral placenta had a significant anterior component with a marginal cord insertion at the inferior margin of its anterior aspect. A vessel coursing over the internal os between the anterior placental cord insertion and a posterior succenturiate lobe was identified on ultrasound (type 2 vasa previa, see Figure 1). The patient's antenatal course was otherwise uneventful. She was counseled for Cesarean delivery at 35-36 weeks to avoid the risk of inadvertent rupture of the vasa previa and fetal exsanguination ${ }^{1,2}$. However, she believed that considering given her past obstetrical history of post -term pregnancies and her closed long cervix, she is was less likely to go into preterm labor or sustain preterm premature rupture of membranes with a disastrous outcome secondary to vasa previa. She therefore declined hospitalization and requested delivery after 37 weeks gestation.

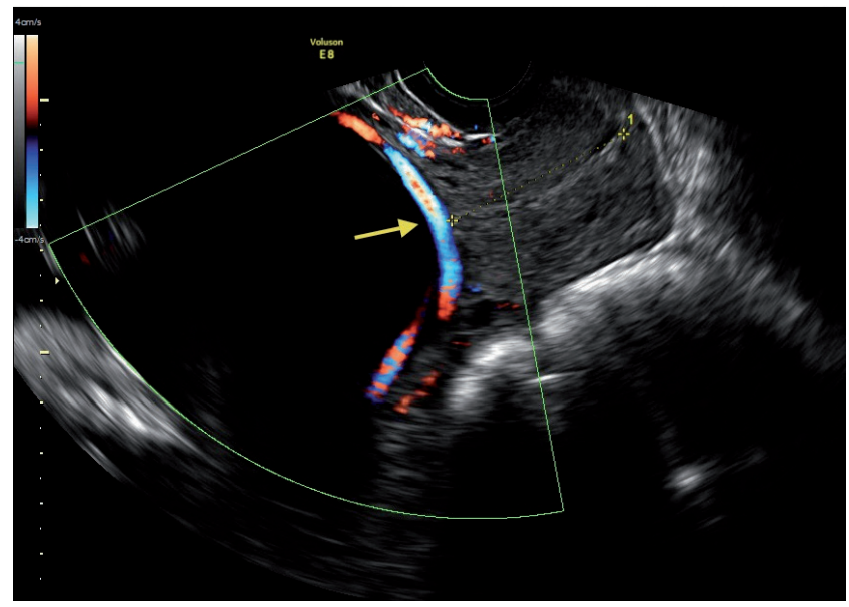

Figure 1. Doppler images showing blood flow through a vasa previa vessel over the internal os between the anterior placental cord insertion and the posterior succenturiate lobe (arrow).

\section{Treatment}

Primary low transverse Cesarean section was performed at 37 weeks and 1 day gestation as per the patient's request. At the time of surgery, the uterine incision was gradually and carefully deepened to allow the membranes to remain intact and bulge out from the incision. This was to avoid making an incision into the amniotic sac prior to localization of the course of the vasa previa vessels in the exposed membranes underneath the uterine incision. Indeed, extensive vasa previa vessels were identified in the intact membranes directly underneath the uterine incision in the lower uterine segment (Figure 2). After identification of the vasa previa vasculature the amnion was incised about one $\mathrm{cm}$ away, remaining parallel to the vessel leaving these vessels intact. Additionally, hemostats were kept available to clamp the vessel on either side if possible extension of the incision into one of the vessels occurred; and followed by expeditious delivery of the baby. A healthy $2980 \mathrm{~g}$ male fetus was delivered with Apgar scores 9, 9 and umbilical cord artery (Ua) pH 7.3.

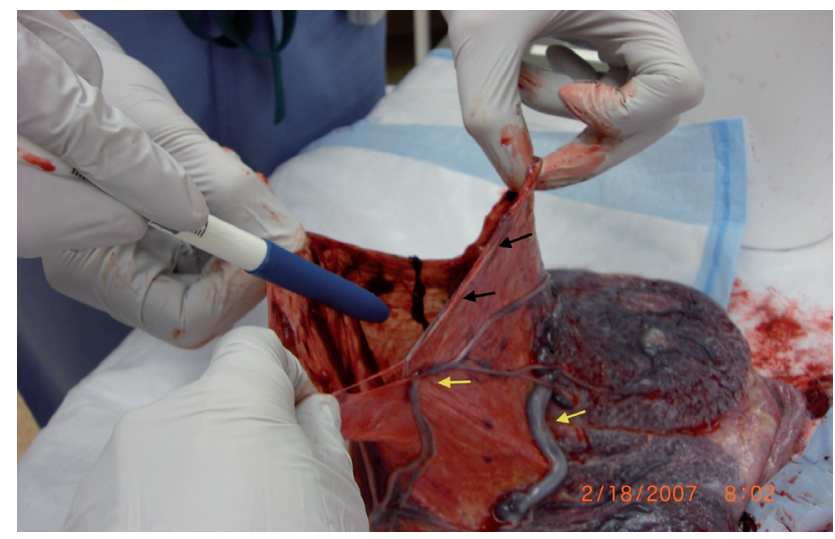

Figure 2. Amniotic sac showing presence of vasa previa vessels running in juxtaposition to the incision through which the baby was delivered, thus avoiding severance of the vessels. The site of amnion incision (black arrows) in the vicinity of but distinct from the vasa previa vessels (yellow arrows).

\section{Discussion}

Vasa previa is a rare $(1: 2500)$ but important and potentially fatal cause of bleeding in the second and third trimester as well as in labor. The condition carries a risk of fetal exsanguination and death when rupture of the membranes involves tearing of vasa previa vessels running within the membranes and carrying fetal blood. Fortunately, the condition can often be diagnosed prenatally by ultrasound examination. Type I vasa previa refers to velamentous insertion of the cord with resultant vasa previa and Type II indicates interconnecting vessels between two lobes of placenta in a bipartite placenta or connecting vessel with a succenturiate lobe of the placenta. Nomiyama et al. identified placental cord insertion site with great degree of certainty at 18-20 weeks gestation and Sepluveda confirmed that gray scale with color Doppler has significant and better accuracy in diagnosing potential abnormal cord insertion and exclude vasa previa than $3 \mathrm{D}^{3,4}$. Situations, where vasa previa should be specifically looked for, include a larger placental mass as it is seen in multiple gestations, particularly those with a high number of fetuses, where there is a greater likelihood of velamentous insertion of the cord, succenturiate lobe or bipartite placenta. Patients with a low lying placenta, particularly if the placental margin appears at the internal os, and pregnancies conceived following in-vitrofertilization constitute 'at risk' groups as well. Favorable outcomes depend on prenatal diagnosis and Cesarean delivery before the rupture of membranes. However, transection of vasa previa vessels during Cesarean delivery itself may cause significant fetal blood loss or exsanguination given the small fetal blood volume. Although the chance of fetal exsanguination during Cesarean section is less common than during vaginal delivery this complication, requiring blood transfusion to the newborn, has been reported ${ }^{4}$. This can be avoided by careful selection of the site of amniotic incision prior to delivery of the fetus. Canterino et al. recommend use of 3D sonography with power Doppler imaging with surface rendering and 3D multiplannar reconstruction to confirm vasa previa and also to map the path of this fetal vessel to prevent laceration of the vessel at cesarean section and fetal exsanguination ${ }^{5}$. According to Oylese et al., 
although 2D and color Doppler sonography is mostly adequate, 3D "allowed precise depiction of complex spatial relationship and confirmed vasa previa" and has an important role in placental abnormalities with uncertain diagnosis ${ }^{6}$. Vaginal ultrasonography (USG) with color Doppler is a recommended way to identify or confirm vasa previa ${ }^{7}$. In a recent case report, the authors published fetoscopic laser coagulation of a type II vasa previa at $325 / 7$ weeks gestation and thereby facilitated an uneventful vaginal delivery, though the authors rightly caution benefits vs. risk of fetoscopy ${ }^{8}$. Earlier, Quintero et al. and others have published early third trimester in-utero laser treatment of type II vasa previa, however these patients had preterm delivery and needed cesarean section ${ }^{9,10}$. Although pre-op mapping of vasa previa by USG is an excellent measure to identify the course of the vasa previa vasculature, considering the recommendations made in this case report could be of additional help in the management of these patients.

\section{Patient perspective}

I would like to thank Dr. Baxi for the most professional, delicate care she provided during my pre-natal care and through the high risk cesarean section.

\section{Consent}

The patient has given written consent for publication of these findings and believes sharing of this information would benefit other patients.

\section{Author contributions}

Both authors have equally participated in preparation of this manuscript. LVB took care of the patient, determined the importance of the topic and prepared the case for publication and modified, proof read the manuscript after preparation by Dr. Neuhausser. Dr. Neuhausser, reviewed the literature, prepared the manuscript, including pictures and in the final format and determined the title of the case report.

\section{Competing interests}

No competing interests were disclosed.

\section{Grant information}

The author(s) declared that no grants were involved in supporting this work.
1. Gagnon R, Morin L, Bly S, et al.: Diagnosic Imaging Committee; Maternal Fetal Medicine Committee Guidelines for the management of vasa previa. $J$ Obstet Gynaecol Can. 2009; 31(8): 748-760. PubMed Abstract | Publisher Full Text

2. Robinson BK, Grobman WA: Effectiveness of timing strategies for delivery of individuals with vasa previa. Obstet Gynecol. 2011; 117(3): 542-549. PubMed Abstract | Publisher Full Text

3. Nomiyama M, Toyota $\mathrm{Y}$, Kawano $\mathrm{H}$ : Antenatal diagnosis of velamentous umbilical cord insertion and vasa previa with color Doppler imaging. Ultrasound Obstet Gynecol. 1998; 12(6): 426-9. PubMed Abstract | Publisher Full Text

4. Sepluveda W, Rojas I, Robert JA, et al:: Prenatal detection of velamentous insertion of the umbilical cord: a prospective color Doppler Ultrasound study. Ultrasound Obstet Gynecol. 2003; 21(6): 564-569. PubMed Abstract | Publisher Full Text

5. Canterino JC, Mondestin-Sorrentino M, Muench MV, et al.: Vasa previa: prenatal diagnosis and evaluation with 3-dimensional sonography and power angiography. J Ultrasound Med. 2005; 24(5): 721-724. PubMed Abstract
6. Oyelese $\mathrm{Y}$, Chavez MR, Yeo L, et al.: Three-dimensional sonographic diagnosis of vasa previa. Ultrasound Obstet Gynecol. 2004; 24(2): 211-5. PubMed Abstract | Publisher Full Text

7. Oyelese $\mathrm{KO}$, Schwärzler $\mathrm{P}$, Coates $\mathrm{S}$, et al.: A strategy for reducing the mortality rate from vasa previa using transvaginal sonography with color Doppler. Ultrasound Obstet Gynecol. 1998; 12(6): 434-438. PubMed Abstract | Publisher Full Text

8. Johnston R, Shrivastava VK, Chmait RH: Term vaginal delivery following fetoscopic laser photocoagulation of type II vasa previa. Fetal Diagn Ther. Online publication. 2013.

PubMed Abstract | Publisher Full Text

9. Quintero RA, Kontopoulos EV, Bornick PW, et al.: In utero laser treatment of type II vasa previa. J Matern Fetal Neonatal Med. 2007; 20(12): 847-851.

PubMed Abstract | Publisher Full Text

10. Chmait $\mathrm{RH}$, Chavira E, Kontopoulos EV, et al:: Third trimester fetoscopic laser ablation of type II vasa previa. J Matern Fetal Neonatal Med. 2010; 23(5): 459-462.

PubMed Abstract | Publisher Full Text 


\section{Open Peer Review}

\section{Current Peer Review Status:}

\section{Version 1}

Reviewer Report 10 July 2014

https://doi.org/10.5256/f1000research.3140.r4572

(C) 2014 Matsuoka R. This is an open access peer review report distributed under the terms of the Creative Commons Attribution License, which permits unrestricted use, distribution, and reproduction in any medium, provided the original work is properly cited.

\section{Ryu Matsuoka}

Department of Obstetrics and Gynecology, Showa University, Tokyo, Japan

This is the case report of vasa previa. It was well described in detail and very helpful to the physician.

Competing Interests: No competing interests were disclosed.

I confirm that I have read this submission and believe that I have an appropriate level of expertise to confirm that it is of an acceptable scientific standard.

Reviewer Report 16 June 2014

https://doi.org/10.5256/f1000research.3140.r5127

(C) 2014 Magann E. This is an open access peer review report distributed under the terms of the Creative Commons Attribution License, which permits unrestricted use, distribution, and reproduction in any medium, provided the original work is properly cited.

\section{Everett Magann}

Department of Obstetrics, University of Arkansas for Medical Sciences, Little Rock, AR, USA

This case report is well written, insightful, and addresses the problems linked with the cesarean delivery for a vasa previa. It describes a technique to ensure the integrity of the fetal vessels located within the membranes as a cesarean delivery is undertaken.

Competing Interests: No competing interests were disclosed.

I confirm that I have read this submission and believe that I have an appropriate level of 
expertise to confirm that it is of an acceptable scientific standard.

Reviewer Report 30 January 2014

https://doi.org/10.5256/f1000research.3140.r2724

(C) 2014 Chao C. This is an open access peer review report distributed under the terms of the Creative Commons Attribution License, which permits unrestricted use, distribution, and reproduction in any medium, provided the original work is properly cited.

\section{Conrad Chao}

University of California, San Francisco, San Francisco, CA, USA

This is an interesting case report with useful suggestions for clinical practice.

Competing Interests: No competing interests were disclosed.

I confirm that I have read this submission and believe that I have an appropriate level of expertise to confirm that it is of an acceptable scientific standard.

The benefits of publishing with F1000Research:

- Your article is published within days, with no editorial bias

- You can publish traditional articles, null/negative results, case reports, data notes and more

- The peer review process is transparent and collaborative

- Your article is indexed in PubMed after passing peer review

- Dedicated customer support at every stage

For pre-submission enquiries, contact research@f1000.com 